\title{
Effect of Chronic Kidney Diseases on Physical Growth and Intelligence Quotient in Children and Adolescents at Assuit Children University hospital.
}

\author{
Kamal , F., El-Zahraa; Abdelaziz .,A \& Elasyed , Y ; Roshdy , A. \\ Departments of Pediatric Nursing, Faculties of Nursing, Assuit and Sohag Universities, \\ Department of Pediatrics, Faculties of Medicine, Assuit University
}

\begin{abstract}
The prevalence of chronic kidney disease is increasing rapidly worldwide. The study aimed at assessing the effect of CKD on physical growth and intelligence quotient of children and adolescents at Assuit Children University Hospital. The study was descriptive comparative study. The study was conducted in Pediatric Nephrology and Dialysis Unit and pediatric nephrology Out-patient clinic in Assuit Children University Hospital. Sample: The study included 62 pediatric patients with chronic kidney diseases aged 2-18 years (CKD children) and 62 apparently healthy children aged 2-18 years who were collected from relatives of the CKD children (healthy children). There are three tools used for collecting data in the study, tool one is an assessment questionnaire sheet for children and parents which included sociodemographic data, past medical history and present medical history of the child. Tool two included anthropometric measurements which were plotted on Egyptian growth charts. Tool Three was stanford-Binet Intelligence Scale (SB 5). The main results of study: There are significantly higher subnormal percentiles in head circumference in CKD children compared to healthy children. There are very significantly higher subnormal percentiles in stature for age percentile, weight for age percentile and total, verbal and nonverbal I.Q in CKD children compared to healthy children. Conclusion: CKD negatively affect physical growth and intelligence quotient in children and adolescents at Assuit Children University Hospital. Recommendations: nurses must make sure the family schedules and keeps follow-up appointments to assess growth, developmental progress, and the effectiveness of treatment plan.
\end{abstract}

\section{Key Words: Chronic Kidney Diseases, Physical Growth, Intelligence Quotient, Pediatric, Nurses}

\section{Introduction:}

Prior to 2002, the term chronic renal insufficiency was used to characterize patients who had progressive decline in renal function, defined as a glomerular filtration rate (GFR) of less than 75 $\mathrm{ml} / \mathrm{min}$ per $1.73 \mathrm{~m}^{2}$ body surface area. Chronic kidney disease (CKD) is the new term defined by the National Kidney Foundation and Kidney Disease Outcome Quality Initiative (KDOQI) Children to classify any patient who has kidney damage lasting for at least 3 months with or without a decreased GFR or any patient who has a GFR of less than 60 $\mathrm{ml} / \mathrm{min}$ per $1.73 \mathrm{~m}^{2}$ lasting for 3 months with or without kidney damage (Whyte and Fine, 2008).

The prevalence of chronic kidney disease is increasing rapidly worldwide (El-Tayeb et al, 2010). The prevalence of CKD in the pediatric population is approximately 18 per 1 million (Kligman et al., 2011 and Axton and Fugate, 2009).

The presentation of CKD can be varied, either due to the primary renal disease or as a consequence of impaired renal function, with onset sometimes being silent with an insidious progression and symptoms only developing late in its course. Even with optimal care, many of these children go on to develop ESRF and require renal replacement therapy (Rashid et al., 2007).
The current CKD classification system described by the National Kidney Foundation's Kidney Disease Outcomes Quality Initiative (NKF-K/DOQI) has helped remedy the situation. According to the $\mathrm{K} / \mathrm{DOQI}$ scheme, CKD is characterized by stage 1 (mild disease) through stage 5 (ESRD) (Bradley et al., 2007).

Growth failure is a common yet complex problem of childhood chronic kidney disease caused by multiple factors encountered due to the primary disease or secondary to the renal impairment. The cause of growth failure in CKD is multifactorial with linear impairment being a final common pathway of various factors including the etiology of CKD, hormonal dysregulation, nutritional deficiency, metabolic acidosis, uremia, chronic anemia and persistent micro inflammation (Rashid et al., 2007).

Management of CKD prior to renal replacement therapy is thus conservative with the main aims being to slow down disease progression, optimize renal function and minimize complications secondary to CKD (Rashid et al., 2007).

Linear growth and neurocognitive development are two of the most important differences between adults and children (Greenbaum et al., 2009). Other disease-specific factors that likely mediate neurocognitive outcomes (e.g., anemia, hypertension, cardiovascular) and endorse the importance of 
continued interdisciplinary research collaborations that will provide a better understanding of the mechanisms responsible for improved neurocognitive functioning after transplantation (Arlene et al., 2006).

Nursing care for patient with renal insufficiency and chronic renal failure is to observe the child for signs of progressive renal impairment. Make sure the family schedules and keeps follow-up appointments to assess growth, developmental progress, and the effectiveness of treatment plan. Family teaching for home management focuses on medication, a diet adequate in protein and calories to support growth, management of acute gastrointestinal illnesses to prevent dehydration, and care of the child with progressive renal insufficiency(Ball and Bindler, 2008).

Aim of the study

Assess the effect of chronic kidney diseases on physical growth and intelligence quotient of children and adolescents at Assuit Children University Hospital.

Research question: Do chronic kidney diseases negatively affect physical growth and intelligence quotient of children and adolescents?

\section{Subjects and Method}

Research design: Comparative research design was used to conduct this study.

Setting:-The study was conducted in Pediatric Nephrology and Dialysis Unit and pediatric nephrology Out-patient clinic in Assuit Children University Hospital.

\section{Subjects:-}

The study included 62 pediatric patients with chronic kidney diseases (convenient sample); 64.5\% had nephrotic syndrome $(32.3 \%$ had steroid dependant nephrotic syndrome, $16.1 \%$ had steroid resistant nephrotic syndrome and $16.1 \%$ had minimal change nephrotic syndrome), $6.5 \%$ had chronic renal failure (not on dialysis), and $29 \%$ had end stage renal disease (on regular dialysis). As well 62 apparently healthy children who were collected from relatives of the CKD children (healthy children). CKD children were divided into two groups; CRF and ESRD group $(n=22)$ and nephrotic syndrome group $(n=40)$.

Inclusion criteria: Children of both sexes, 2-18 years old with chronic kidney diseases.

\section{Exclusion criteria:}

Children presenting with massive edema, other chronic diseases that may affect growth such as tuberculosis, bronchial asthma, diabetes mellitus, congenital heart diseases and any neurocognitive impairments.
Tools of the Study:

Tool 1:- Assessment questionnaire sheet for children and parents developed by the researcher through reviewing related literature which includes:

1. Sociodemographic data of child such as name, age, sex, birth order, parents' education, family income, degree of relativeness between parents, number of siblings and residence.

2. Past medical history such as dehydration, hypotension, hypertension, congenital anomalies, severe burns, hemorrhage, post infectious glomerulonephritis and nephrotoxins.

3. Present medical history such as diagnosis, family history, duration of disease, stage, etiology and modes of presentation.

Tool 2:Anthropometric measurements sheet was used to record weight, stature, head circumference, chest circumference, skin fold thickness, mid-arm circumference, BMI, weight for age, stature for age, head circumference for age and BMI for age percentiles. Egyptian growth charts were used to plot growth measurements (DEMPU, 2008).

Tool 3:Stanford- Binet Intelligence Scale (SB 5). It is a standardized test that assesses IQ and cognitive abilities in children and adults. It provides comprehensive coverage of five factors of cognitive ability: Fluid Reasoning, knowledge, quantitative processing, visual-spatial processing and working memory (Gale Roid, 2003).

\begin{tabular}{|l|l|}
\hline $\begin{array}{l}\text { MeasureIQ } \\
\text { Range }\end{array}$ & \multicolumn{1}{c|}{ Category } \\
\hline $\mathbf{1 4 5 - 1 6 0}$ & $\begin{array}{l}\text { Very gifted or highly } \\
\text { advanced }\end{array}$ \\
\hline $\mathbf{1 3 0 - 1 4 4}$ & Gifted or very advanced \\
\hline $\mathbf{1 2 0 - 1 2 9}$ & Superior \\
\hline $\mathbf{1 1 0 - 1 1 9}$ & High average \\
\hline $\mathbf{9 0 - 1 0 9}$ & Average \\
\hline $\mathbf{8 0 - 8 9}$ & Low average \\
\hline $\mathbf{7 0 - 7 9}$ & $\begin{array}{l}\text { Borderline impaired or } \\
\text { delayed }\end{array}$ \\
\hline $\mathbf{5 5 - 6 9}$ & Mildly impaired or delayed \\
\hline $\mathbf{4 0 - 5 4}$ & $\begin{array}{l}\text { Moderately impaired or } \\
\text { delayed }\end{array}$ \\
\hline $\mathbf{2 5 - 3 9}$ & Severely impaired or delayed \\
\hline
\end{tabular}

Tool Three: Stanford- Binet Intelligence Scale (SB 5). It is a standardized test that assesses IQ and cognitive abilities in children and adults. It provides comprehensive coverage of five factors of cognitive ability: Fluid Reasoning, knowledge, quantitative processing, visual-spatial processing and working memory (Gale Roid, 2003). 


\section{Methods of data collection:}

1. Reviewing of the related literature to assess the effect of chronic kidney diseases on physical growth and intelligence quotient of children and adolescents.

2. An official permission was obtained from the head of the selected departments (Assuit Children University Hospital) to collect the necessary data for the study

3. Oral consent was obtained from the children and parents to collect data after complete explanation of the purpose of the study. They advised of their right to withdraw from the study at any point, and that their participation status did not affect the care they received. Names were coded for data entry so that; their names could not be identified.

4. Tools 1\&2 were developed by researcher \& tested for its content validity by five experts in the pediatrics field.

5. A pilot study: It was carried out on 10 children who suffered from CKD for testing the clarity and applicability of the study tools and estimate the length of time needed to fill the study tools. According to the results of the pilot study, the essential modifications were done and the final form was developed. Children of the pilot study were excluded from the sample.

6. Field of the work: The data were collected at four days of the week (Saturday, Sunday, Monday and Friday) during the period between September 2011 till June 2012 .The parents and their children were individually interviewed to fill the study tools at Pediatric Nephrology and Dialysis Unit and pediatric nephrology Outpatient clinic in Assuit Children University Hospital. The time used for filling study tools for one child ranged between 75- 95 minutes for tool three and 15-20 minutes for tools 1 and 2 . Throughout the interview relative information was recorded in the designed study tools depending upon the response of the participant.

7. Anthropometric measurements for children were done and data was collected by the investigator through personal interviewing defined tools. Health resources administration standard was used to compare all growth parameters between CKD children and healthy children at $<5^{\text {th }} ; 5^{\text {th }}-95^{\text {th }}$ and $>95^{\text {th }}$ percentile.

8. Measuring I.Q for children with Stanford-Binet Intelligence Scale (full scale), fifh edition (SB 5 by the researcher after training for three weeks by specialist.

\section{Statistical analysis:}

The data obtained were reviewed, prepared for computer entry, coded, analyzed and tabulated. Data entry and analysis were done using SPSS version 16 statistical software package. Data were presented using descriptive statistics in the form of frequencies and percentages for qualitative variables, means and standard deviations for quantitative variables. Quantitative continuous data were compared using analysis of variance test in case of comparisons between two independent children. Using t.test in case of comparisons between two children. Using Chi. Square to determine significance for nonparametric variable. Using Pearson's correlation for numeric variable in the same children. For each test level of significance $(\mathrm{P})$ was considered as follows:no significance $p>0.05$, significant difference at $p \leq$ 0.05 , significant difference at $\mathrm{p} \leq 0.01$, significant difference at $\mathrm{p} \leq 0.00$

\section{Results}

Table (1): Sociodemographic Characteristics of CKD and Healthy Children (No= 124).

\begin{tabular}{|c|c|c|c|c|c|c|}
\hline \multirow{2}{*}{ Items } & \multicolumn{2}{|c|}{ CKD children } & \multicolumn{2}{|c|}{ Healthy children } & \multirow{2}{*}{$\mathbf{X}^{2}$} & \multirow{2}{*}{ p- valuc } \\
\hline & No & $\%$ & No & $\%$ & & \\
\hline $\begin{array}{l}\text { Age (years) } \\
2-<6 \\
6-<10 \\
10-<14 \\
14-18 \\
\end{array}$ & $\begin{array}{l}10 \\
16 \\
22 \\
14 \\
\end{array}$ & $\begin{array}{l}16.1 \\
25.8 \\
35.5 \\
22.6 \\
\end{array}$ & $\begin{array}{l}14 \\
15 \\
21 \\
12 \\
\end{array}$ & $\begin{array}{l}22.6 \\
24.2 \\
33.9 \\
19.4 \\
\end{array}$ & 0.876 & 0.831 \\
\hline Mean \pm SD & \multicolumn{2}{|c|}{$10 \pm 4$ years } & \multicolumn{4}{|c|}{$9.6 \pm 4$ years } \\
\hline $\begin{array}{l}\text { Sex } \\
\text { Male } \\
\text { Female } \\
\end{array}$ & $\begin{array}{l}28 \\
34 \\
\end{array}$ & $\begin{array}{l}45.2 \\
54.8 \\
\end{array}$ & $\begin{array}{l}28 \\
34 \\
\end{array}$ & $\begin{array}{l}45.2 \\
54.8 \\
\end{array}$ & 0.000 & 1.000 \\
\hline $\begin{array}{l}\text { Residence } \\
\text { Rural } \\
\text { Urban }\end{array}$ & $\begin{array}{l}51 \\
11\end{array}$ & $\begin{array}{l}82.3 \\
17.7\end{array}$ & $\begin{array}{c}56 \\
6\end{array}$ & $\begin{array}{c}90.3 \\
9.7\end{array}$ & 1.091 & 0.296 \\
\hline
\end{tabular}




\begin{tabular}{|l|c|c|c|c|c|c|}
\hline \multirow{2}{*}{ Items } & \multicolumn{2}{|c|}{ CKD children } & \multicolumn{2}{c|}{ Healthy children } & \multirow{2}{*}{$\mathbf{X}^{2}$} & \multirow{2}{*}{ p- value } \\
\cline { 2 - 6 } & No & \% & No & \% & & \\
\hline Birth order & & & & & \\
$1^{\text {st }}$ & 13 & 21 & 13 & 21 & \\
$2^{\text {nd }}$ & 16 & 25.8 & 12 & 19.4 & \\
$3^{\text {rd }}$ & 6 & 9.7 & 15 & 24.2 & $\mathbf{5 . 0 3 6}$ & $\mathbf{0 . 4 1 2}$ \\
$4^{\text {th }}$ & 11 & 17.7 & 8 & 12.9 & & \\
$5^{\text {th }}$ & 8 & 12.9 & 7 & 11.3 & & \\
$>^{\text {th }}$ & 8 & 12.9 & 7 & 11.3 & & \\
\hline
\end{tabular}

Table (2): Percentage Distribution of CKD Children According to Etiology of CKD (No=62).

\begin{tabular}{|l|c|c|}
\hline \multicolumn{1}{|c|}{ Etiology of CKD } & \multicolumn{2}{c|}{ CKD children } \\
\cline { 2 - 3 } & No & \% \\
\hline Congenital abnormalities and hereditary conditions & 12 & 19.2 \\
Nephrotic syndrome & 41 & 66.2 \\
Multisystem conditions & 3 & 4.8 \\
Unknown & 6 & 9.7 \\
\hline
\end{tabular}

Table (3): Comparison of the Anthropometric Measurements in Both CKD and Healthy Children According to body mass index Percentile, Stature for Age Percentile, Weight for Age Percentile and Head Circumference for Age Percentile (No=124).

\begin{tabular}{|c|c|c|c|c|c|c|}
\hline \multirow{2}{*}{ Items } & \multicolumn{2}{|c|}{ CKD children } & \multicolumn{2}{|c|}{ Healthy children } & \multirow{2}{*}{$\mathbf{X}^{2}$} & \multirow{2}{*}{ p- value } \\
\hline & No & $\%$ & No & $\%$ & & \\
\hline $\begin{array}{l}\text { Body mass index percentile } \\
\text { Underweight }\left(<5^{\text {th }} \text { percentile }\right) \\
\text { Normal weight }\left(5^{\text {th }}-85^{\text {th }} \text { percentile }\right) \\
\text { Overweight }\left(>85^{\text {th }}-95^{\text {th }}\right) \\
\left.\text { Obesity (more than } 95^{\text {th }} \text { percentile }\right)\end{array}$ & $\begin{array}{l}13 \\
47 \\
1 \\
1\end{array}$ & $\begin{array}{l}21 \\
75.8 \\
1.6 \\
1.6\end{array}$ & $\begin{array}{l}8 \\
51 \\
2 \\
1\end{array}$ & $\begin{array}{l}12.9 \\
82.3 \\
3.2 \\
1.6\end{array}$ & 1.687 & 0.640 \\
\hline $\begin{array}{l}\text { Stature for age percentile } \\
\text { Subnormal }\left(<5^{\text {th }} \text { percentile }\right) \\
\text { Normal }\left(5^{\text {th }}-95^{\text {th }} \text { percentile }\right)\end{array}$ & $\begin{array}{l}33 \\
29\end{array}$ & $\begin{array}{l}53.2 \\
46.8\end{array}$ & $\begin{array}{l}7 \\
55\end{array}$ & $\begin{array}{l}11.3 \\
88.7\end{array}$ & 23.065 & $0.000 * * *$ \\
\hline $\begin{array}{l}\text { Weight for age percentile } \\
\text { Subnormal }\left(<5^{\text {th }} \text { percentile }\right) \\
\text { Normal }\left(5^{\text {th }}-95^{\text {th }} \text { percentile }\right)\end{array}$ & $\begin{array}{l}33 \\
29\end{array}$ & $\begin{array}{l}53.2 \\
46.8\end{array}$ & $\begin{array}{l}11 \\
51\end{array}$ & $\begin{array}{l}17.7 \\
82.3\end{array}$ & 15.535 & $0.000 * * *$ \\
\hline $\begin{array}{l}\text { Head circumference for age percentile } \\
\quad \text { Subnormal }\left(<5^{\text {th }} \text { percentile }\right) \\
\text { Normal }\left(5^{\text {th }}-95^{\text {th }} \text { percentile }\right) \\
\left.\text { Abnormal (more than } 95^{\text {th }} \text { percentile }\right)\end{array}$ & $\begin{array}{l}3 \\
59 \\
0\end{array}$ & $\begin{array}{l}4.8 \\
95.2 \\
0\end{array}$ & $\begin{array}{l}0 \\
57 \\
5\end{array}$ & $\begin{array}{l}0 \\
91.9 \\
8.1\end{array}$ & 8.034 & $0.018 *$ \\
\hline
\end{tabular}

$*=$ there is statistically significant difference at $p \leq 0.05, * *=$ there is high statistically significant difference at $p$ $\leq 0.01, * * *=$ there is very high statistically significant difference at $p \leq 0.001$

Table (4): Comparison between Anthropometric Measurements in Both CKD and Healthy Children (No=124).

\begin{tabular}{|l|l|l|l|}
\hline \multirow{2}{*}{ Items } & CKD children & Healthy children & \multirow{2}{*}{ p-value } \\
\cline { 2 - 4 } & mean \pm SD & mean \pm SD & $0.04 *$ \\
\hline Weight $(\mathrm{kg})$ & $25.919 \pm 9.079$ & $30.097 \pm 12.961$ & $0.05^{*}$ \\
\hline Stature $(\mathrm{cm})$ & $123.645 \pm 17.096$ & $129.540 \pm 22.198$ & 0.147 \\
\hline Head circumference $(\mathrm{cm})$ & $51.291 \pm 1.883$ & $52.032 \pm 2.427$ & 0.339 \\
\hline Chest circumference $(\mathrm{cm})$ & $63.694 \pm 9.0488$ & $63.815 \pm 10.088$ & 0.349 \\
\hline Mid-arm circumference $(\mathrm{cm})$ & $17.968 \pm 3.609$ & $18.766 \pm 3.465$ & \\
\hline
\end{tabular}




\begin{tabular}{|l|l|l|l|}
\hline \multirow{2}{*}{ Items } & CKD children & Healthy children & \multirow{2}{*}{ p-value } \\
\cline { 2 - 4 } & mean \pm SD & mean \pm SD & \\
\hline BMI $(\%)$ & $16.487 \pm 2.566$ & $17.090 \pm 2.994$ & 0.476 \\
\hline Skin fold thickness (mm) & $8.669 \pm 3.610$ & $11.169 \pm 4.995$ & $0.002 * *$ \\
\hline
\end{tabular}

$*=$ there is statistically significant difference at $\mathrm{p} \leq 0.05, * *=$ there is high statistically significant difference at $\mathrm{p} \leq 0.01$

Table (5): Percentage Distribution of Both CKD and Healthy Children According to Total Intelligence Quotient (No=124).

\begin{tabular}{|l|l|l|l|l|l|l|}
\hline \multirow{2}{*}{ Total I.Q. } & \multicolumn{2}{|l|}{ CKD children } & \multicolumn{2}{l|}{ Healthy children } & \multirow{2}{*}{$\mathbf{X}^{2}$} & \multirow{2}{*}{ p- value } \\
\cline { 2 - 5 } & No & \% & No & \% & & \\
\hline 120- 129 (superior) & 1 & 1.6 & 3 & 4.8 & \\
110- 119 (higher than average) & 3 & 4.8 & 15 & 24.2 & \\
90- 109 (average) & 30 & 48.4 & 42 & 67.7 & 33.640 & \\
80- 89 (lower than average) & 23 & 37.1 & 2 & 3.2 & \\
70- 79 (on the borders of retardation) & 4 & 6.5 & 0 & 0 & \\
55- 69 (mild retardation) & 1 & 1.6 & 0 & 0 & & \\
\hline
\end{tabular}

$* * *=$ there is very high statistically significant difference

Table (6): Comparison between Verbal I.Q, Nonverbal I.Q and Total I.Q in Both CKD and Healthy Children $(\mathbf{N o}=124)$.

\begin{tabular}{|l|l|l|l|}
\hline \multirow{2}{*}{ Items } & CKD children & Healthy children & \multirow{2}{*}{ p- value } \\
\cline { 2 - 4 } & mean \pm SD & mean \pm SD & \\
\hline Verbal I.Q & $91.58 \pm 12.831$ & $104.34 \pm 7.680$ & $0.000^{* * *}$ \\
\hline Nonverbal I.Q & $90.87 \pm 10.883$ & $105.32 \pm 9.869$ & $0.000^{* * *}$ \\
\hline Total I.Q & $91.45 \pm 10.531$ & $104.87 \pm 8.350$ & $0.000^{* * *}$ \\
\hline
\end{tabular}

$* * *=$ there is very high statistically significant difference at $\mathrm{p} \leq 0.001$

Table (7): Comparison between Anthropometric Measurements in Children with CRF and ESRD and Their Healthy Children According to Weight, Stature, Head Circumference, Mid-Arm Circumference, Chest Circumference, BMI and Skin Fold Thickness (No=44).

\begin{tabular}{|c|c|c|c|}
\hline \multirow{2}{*}{ Items } & CRF and ESRD children & Healthy children & \multirow{2}{*}{ p-value } \\
\hline & mean \pm SD & mean \pm SD & \\
\hline Weight (kg) & $28.532 \pm 7.143$ & $34.136 \pm 12.474$ & 0.074 \\
\hline Stature (cm) & $130.545 \pm 12.53$ & $136.136 \pm 17.396$ & 0.228 \\
\hline Head circumference (cm) & $51.889 \pm 1.811$ & $52.705 \pm 2.383$ & 0.208 \\
\hline Chest circumference $(\mathrm{cm})$ & $65.682 \pm 7.267$ & $66.341 \pm 8.471$ & 0.783 \\
\hline Mid-arm circumference $(\mathrm{cm})$ & $17.250 \pm 2.039$ & $20.136 \pm 3.036$ & $0.001 * * *$ \\
\hline BMI (\%) & $16.491 \pm 2.172$ & $17.818 \pm 3.403$ & $0.001 * * *$ \\
\hline Skin fold thickness (mm) & $7.455 \pm 3.450$ & $12.045 \pm 5.625$ & $0.002 * *$ \\
\hline
\end{tabular}

$* *=$ there is high statistically significant difference at $p \leq 0.01, * * *=$ there is statistically significant difference at $p \leq 0.001$ 
Table (8): Comparison between Total I.Q, Nonverbal I.Q and Verbal I.Q in CRF and ESRD Children and Their Healthy Children $(\mathrm{No}=44)$.

\begin{tabular}{|l|l|l|l|}
\hline \multirow{2}{*}{ Items } & CRF and ESRD children & Healthy children & \multirow{2}{*}{ p-value } \\
\cline { 2 - 4 } & mean \pm SD & mean \pm SD & \\
\hline Total I.Q & $90.50 \pm 12.546$ & $104.27 \pm 7.808$ & $0.001 * * *$ \\
\hline Nonverbal I.Q & $89.95 \pm 12.116$ & $104.9 \pm 8.837$ & $0.001 * * *$ \\
\hline Verbal I.Q & $90.59 \pm 15.333$ & $104.36 \pm 7.234$ & $0.001 * * *$ \\
\hline
\end{tabular}

$* * *=$ there is very high statistically significant difference at $\mathrm{p} \leq 0.001$

Table (9): Comparison Between Anthropometric Measurements in Children With Nephrotic syndrome and Their Healthy Children According to Weight, Stature, Head Circumference, Chest Circumference, Midarm Circumference BMI and Skin Fold Thickness $(\mathrm{No}=80)$.

\begin{tabular}{|l|l|l|l|}
\hline \multirow{2}{*}{\multicolumn{1}{|c|}{ Items }} & \multicolumn{1}{c|}{ Nephrotic Syndrome children } & \multicolumn{1}{c|}{ Healthy children } & \multirow{2}{*}{ p-value } \\
\cline { 2 - 4 } & \multicolumn{1}{|c|}{ mean \pm SD } & \multicolumn{1}{|c|}{ mean \pm SD } & \\
\hline Weight $(\mathbf{k g})$ & $24.488 \pm 9.774$ & $27.875 \pm 12.833$ & 0.188 \\
\hline Stature $(\mathbf{c m})$ & $119.850 \pm 18.192$ & $125.913 \pm 23.869$ & 0.205 \\
\hline Head circumference $(\mathbf{c m})$ & $50.963 \pm 1.861$ & $51.663 \pm 2.400$ & 0.149 \\
\hline Chest circumference $(\mathbf{c m})$ & $62.600 \pm 9.806$ & $62.425 \pm 10.721$ & 0.939 \\
\hline Mid-arm circumference $(\mathbf{c m})$ & $18.363 \pm 4.206$ & $18.013 \pm 3.489$ & 0.687 \\
\hline BMI $(\%)$ & $16.485 \pm 2.785$ & $16.690 \pm 2.706$ & 0.739 \\
\hline Skin fold thickness $(\mathbf{m m})$ & $9.338 \pm 3.561$ & $10.688 \pm 4.617$ & 0.147 \\
\hline
\end{tabular}

Table (10): Comparison between I.Q, Nonverbal I.Q and Verbal I.Q in Nephrotic Syndrome Children and Their Healthy Children $(\mathrm{No}=80)$.

\begin{tabular}{|l|l|l|l|}
\hline \multirow{2}{*}{\multicolumn{1}{|c|}{ Items }} & Nephrotic syndrome children & \multicolumn{1}{c|}{ Healthy children } & \multirow{2}{*}{ p-value } \\
\cline { 2 - 3 } & \multicolumn{1}{|c|}{ mean \pm SD } & \multicolumn{1}{c|}{ mean \pm SD } & \\
\hline Verbal I.Q & $92.13 \pm 11.404$ & $104.33 \pm 8.004$ & $0.001^{* * *}$ \\
\hline Nonverbal I.Q & $91.38 \pm 10.270$ & $106.00 \pm 10.439$ & $0.001^{* * *}$ \\
\hline Total I.Q & $91.98 \pm 9.377$ & $105.20 \pm 8.713$ & $0.001 * * *$ \\
\hline
\end{tabular}

$* * *=$ there is very high statistically significant difference at $p \leq 0.001$

Table 1 shows that nearly more than half of CKD children were females $(54.8 \%)$ and the majority of them were living in the rural areas (82.3\%) and the highest percentage of children suffering from CKD was between 10 to $<14$ years $(35.5 \%)$. Regarding age mean \pm SD, it was $120.476 \pm 47.653$ months.

Table 2 shows that congenital abnormalities and hereditary conditions represent $19.2 \%$, nephrotic syndrome $66.2 \%$, multisystem conditions $4.8 \%$ and unknown $9.7 \%$.

Table 3 shows significantly higher subnormal percentiles $\left(<5^{\text {th }}\right.$ percentile $)$ in head circumference in CKD children compared to healthy children. There are very significantly higher subnormal percentiles in stature for age percentile $(53.2 \%$ vs. $11.3 \%$ respectively) and weight for age percentile in CKD children compared to healthy children $(53.2 \%$ vs. $17.7 \%$ respectively).
Table 4 shows means of head circumference, chest circumference, mid-arm circumference and BMI, no statistical significant differences were found. Regarding weight of CKD and healthy children, there was a statistical significant difference (mean $\pm \mathrm{SD}=$ $25.919 \pm 9.079$ and $30.097 \pm 12.961$ respectively). Regarding height of CKD and healthy children, there was a statistical significant difference (mean $\pm \mathrm{SD}=$ $123.645 \pm 17.096$ and $129.540 \pm 22.198$ respectively). Regarding skin fold thickness there was a high statistical significant difference (mean $\pm \mathrm{SD}=8.669 \pm$ 3.610 and $11.169 \pm 4.995$ respectively).

Table 5 shows very high statistical significant differences between CKD and healthy children as regard total I.Q, $1.6 \%$ of CKD children and $4.8 \%$ of healthy children were superior (120-129), $4.8 \%$ and $24.2 \%$ respectively had higher than average scores (110- 119). The highest percentage in CKD and healthy children ( $48.4 \%$ and $67.7 \%$ respectively) had 
average scores (90- 109), 37.1\% and $3.2 \%$ respectively were lower than average (80-89), $6.5 \%$ and $0 \%$ respectively were on the borders of retardation (70-79) and $1.6 \%$ and $0 \%$ respectively had mild retardation (55-69).

Table 6 shows very high statistical significant differences between mean \pm SD of CKD and healthy children as regards total I.Q, non verbal I.Q and verbal I.Q.

Table 7 shows anthropometric measurements in children with CRF and ESRD and their healthy children; regarding to mean \pm SD of stature, weight, head circumference and chest circumference there were no statistical significant differences. Regarding to mid-arm circumference and BMI there were very high statistical significant differences (mean \pm SD of MAC $(\mathrm{cm})$ were $17.250 \pm 2.039$ and $20.136 \pm 3.036$ respectively and BMI (\%) were 16.491 \pm 2.172 and $17.818 \pm 3.403$ respectively). Regarding to skin fold thickness there were high statistical significant differences (mean \pm SD were 7.455 \pm 3.450 and $12.045 \pm 5.625$ respectively).

Table 8 shows very high statistical significant differences between mean $\pm \mathrm{SD}$ of total I.Q, nonverbal I.Q and verbal I.Q in CRF and ESRD children and their healthy children. Also there were very high statistical significant differences between mean \pm SD of I.Q in nephrotic syndrome children and their healthy children.

\section{Discussion}

It was observed that nearly more than half of CKD children were females $(54.8 \%)$ and the majority of them were living in the rural areas $(82.3 \%)$. This observation may be explained by that rural families are often from low socioeconomic strata, which in turn seek medical advice in the local unequipped health units or may delay seeking medical advice. Also this may be explained by more than half $(58.1 \%)$ of mothers and $40.4 \%$ of fathers were illiterate/ read and write.

This finding is in contrast with those of Ragab $\mathbf{M}$ and Ragab A, 2007 in Mansoura Children University hospital which stated that $32 \%$ were females and $68 \%$ were males. Also Ahmadzadeh et al., 2009 in their study in Iran stated that, among 181 studied children, $58 \%$ were males and Mohamed, 2008 found that $56.7 \%$ were males and $43.3 \%$ were females, $5 \%$ were living in urban and $95 \%$ were living in rural areas in studying 60 children 6- 12 years with nephrotic syndrome in Assuit children University Hospital.

In the current study the highest percentage of children suffering from CKD was between 10 to <14 years (35.5\%). Regarding age mean \pm SD, it was $120.476 \pm$
47.653 months. These findings are consistent with those of Hooper et al., 2011 which were 10- 13 years (33.4\%) and in Zagazig university hospital a study was done on 15 pediatric patients with ESRD on regular hemodialysis between 5 and 14 years (mean age 10.6 \pm 2.8 years) by Youssef et al., 2012. These findings are in contrast with those of Mohamed, 2008 in which sociodemographic data showed that highest percent of school-age children with nephrotic syndrome (60 cases) between 6- 8 years were $48.3 \%$ in Assuit Children University hospital.

In the present study congenital abnormalities and hereditary conditions represents $19.2 \%$, nephrotic syndrome $66.2 \%$, multisystem conditions $4.8 \%$ and unknown 9.7\%. In the other hand Ahmadzadeh et al., 2009 in their study in Iran stated that congenital malformations and hereditary conditions were the commonest cause of CKD (67.6\%), multisystemic diseases $4.3 \%$, chronic glomerulonephritis $6.5 \%$, and miscellaneous and unknown $10.8 \%$ for each one.

In the current study there are significantly higher subnormal percentiles $\left(<5^{\text {th }}\right.$ percentile $)$ in head circumference in CKD children compared to healthy children. There are very significantly higher subnormal percentiles in stature for age percentile (53.2\% vs. $11.3 \%$ respectively) and weight for age percentile in CKD children compared to healthy children(53.2\% vs. $17.7 \%$ respectively).

According to means of stature, head circumference, chest circumference, mid-arm circumference and BMI no statistical significant differences were found. These findings may be explained by age variations in two children, $66.1 \%$ of children were in first stage of CKD also the highest percentage $(35.5 \%)$ was during the first year of diagnosis with CKD.

Regarding weight of CKD and healthy children, there was a statistical significant difference (mean \pm $\mathrm{SD}=25.919 \pm 9.079$ and 30.097 \pm 12.961 respectively). Regarding height of CKD and healthy children, there was a statistical significant difference (mean $\pm \mathrm{SD}=123.645 \pm 17.096$ and $129.540 \pm 22.198$ respectively). Regarding skin fold thickness there was a high statistical significant difference (mean $\pm \mathrm{SD}=8.669 \pm 3.610$ and $11.169 \pm$ 4.995 respectively), these finding can be explained by pathophysiology of disease.

Anthropometric measurements in children with CRF and ESRD and their healthy children in the current study; regarding to mean $\pm \mathrm{SD}$ of stature, weight, head circumference and chest circumference there were no statistical significant differences. Regarding to mid-arm circumference and BMI there were very high statistical significant differences (mean \pm SD of MAC $(\mathrm{cm})$ were $17.250 \pm 2.039$ and $20.136 \pm 3.036$ respectively and 
BMI (\%) were 16.491 \pm 2.172 and $17.818 \pm 3.403$ respectively). Regarding to skin fold thickness there were high statistical significant differences (mean \pm SD were $7.455 \pm 3.450$ and $12.045 \pm 5.625$ respectively). Retarded growth can be explained by pathophysiologic changes of CKD (e.g., hypertension, anemia, hyperparathyroidism and growth hormone resistance) and decreased health care related to nutritional disorders.

In the current study, anthropometric measurements in children with nephrotic syndrome and their healthy children according to BMI, stature, weight, head circumference, chest circumference, mid-arm circumference and skin fold thickness, there were no statistical significant differences. These findings can be explained by all children with nephrotic syndrome had mild renal impairments, also may be due to variations in age of children in both children.

In the same line, Foster and Leonard, 2004 stated that Mild-to-moderate deficits in triceps skin fold thickness have been reported in children with CKD. Abudaif, 2004 studied 50 infants and children (6 months- 14 years) with chronic kidney diseases in Sohag University Hospital and stated that mean \pm SD of weight of patient with chronic renal diseases was significantly lower than that of the control subjects $(12.38 \pm 6.12$ and $17.76 \pm 6.13$ respectively, $P<$ 0.001), only 17 patients showed ideal weight for age and only 7 patients showed head circumference for age $<5^{\text {th }}$ percentiles but, in the other hand Abudaif, 2004 found that means and standard deviations of height, head circumference and mid-arm circumference of patient with chronic renal diseases was significantly lower than that of the control subjects $(93.66 \pm 18.53,47.89 \pm 2.99 \& 10.05 \pm 3.9$ respectively).

Also in the same line Gupta et al., 2011 found that Kuwaiti patients with ESRF had a lower body mass index when compared with the controls. Moreover, Bahbah et al., 2011 found that no statistical significant differences in height and weight between conservative children and their controls (mean \pm SD of weight $=12.73 \pm 4.68$ and $12.4 \pm 3.56$ respectively; mean \pm SD of height $=136.8 \pm 28.89$ and $147.1 \pm 13.95$ respectively). As regard dialysis and control children, they found high significant statistical difference between their weights $(\mathrm{P}<0.001)$ and no significant statistical difference between their heights $p>0.05$, mean \pm SD=136 $\pm \mathbf{1 2 . 0 8}$ and $147.1 \pm 13.95$ respectively, as regard conservative and control children, they found no significant statistical difference between their weights $(\mathrm{P}>0.05)$ and no significant statistical difference between their heights (p>0.05).

In the current study there are very high statistical significant differences between CKD and healthy children as regard total I.Q, $1.6 \%$ of CKD children and $4.8 \%$ of healthy children were superior (120$129), 4.8 \%$ and $24.2 \%$ respectively had higher than average scores (110-119). The highest percentage in CKD and healthy children $(48.4 \%$ and $67.7 \%$ respectively) had average scores (90- 109), 37.1\% and $3.2 \%$ respectively were lower than average (80$89), 6.5 \%$ and $0 \%$ respectively were on the borders of retardation (70-79) and $1.6 \%$ and $0 \%$ respectively had mild retardation (55- 69). These findings may relate to the effects of disease chronicity, disease progression, age of onset, anemia, protein loss and hypertension.

There were very high statistical significant differences between mean \pm SD of CKD and healthy children as regards total I.Q, non verbal I.Q and verbal I.Q. There were very high statistical significant differences between mean \pm SD of total I.Q, nonverbal I.Q and verbal I.Q in CRF and ESRD children and their healthy children. Also there were very high statistical significant differences between mean \pm SD of I.Q in nephrotic syndrome children and their healthy children.

In the same line Warady et al., 1999 reported a relatively intact I.Q, with 15 of $19(79 \%)$ in the average range. In this children, 13 of $18(72 \%)$ achieved average verbal I.Q scores, while only 10 $(56 \%)$ scored in the average range in the nonverbal subtest in 19 children with a mean age of $6.6 \pm 1.3$ years who had ESRD from infancy, also Brouhard et al., 2000 described a significantly lower I.Q in the children with kidney disease compared with their sibling controls, Gipson et al., 2006 revealed a significant difference between the children in I.Q, with the typical children being significantly higher than the CKD children.

Also findings of Duquete et al., 2007 suggested that children with CKD may be vulnerable to subtle, specific deficits in domains of attention relative to their typically-developing peers, results also suggested that this finding of specific attention problems may be particularly relevant for children with more severe levels of CKD. Moreover, Amr et al., 2013 in their study at Mansoura University Children hospital on 24 children with CKD, and 12 children as controls between the ages of ten years and 15 years were assessed using the Wechsler Intelligence Scale for Children (WISC). Mean scores in verbal, performance, and full scale I.Q were significantly lower in the predialysis and dialysis children than in the healthy children. 


\section{Conclusion}

The present study concluded that children and adolescents with CKD had lower growth parameters and lower IQ scores compared to normal children.

\section{Recommendations}

1. Heath education sessions should be conducted to mothers and children to improve the compliance to the prescribed treatment as well as to help them to adapt with their limitation of the disease and its management.

2. Early nutritional intervention and the prevention and treatment of metabolic deficits are key components in the preservation of growth in a child with CKD.

3. Awareness of individuals at an increased risk, along with early diagnosis and adequate management of many predisposing conditions could prevent progression to more severe renal disease which has potentially devastating effects on every aspect of a child's life.

4. The recognition that a child has growth failure in its most early stages and treating its causes will have a significant long term effect on the medical and psychosocial outcome of the child with CKD.

5. Educational and psychosocial supports are critical for children with CKD, and it may be important to monitor their cognitive functioning and academic progress over time.

6. Recombinant human growth hormone therapy should be introduced as early as possible when appropriate.

\section{References:}

1. Abudaif $\mathbf{H}$ (2004): Clinical and some hormonal studies in infants and children with chronic renal diseases in Sohag university hospital, thesis for $\mathrm{PhD}$, Sohag university, Egypt; P 140- 144.

2. Ahmadzadeh A, Valavi E, Zangeneh-Kamali $M$ and Ahmadzadeh A (2009): Chronic kidney disease in southwestern Iranian children, Iran Journal of Pediatrics, 19 (2); P 147.

3. Amr M, El-Gilany A, Bakr A and ElSheshtawy E (2013): Assessing the intelligence of children with chronic kidney diseases, Saudi Journal of Kidney Diseases and Transplantation, Mansoura University, Egypt, 24 (1) P 67-71.

4. Arlene $C$, Robert B, Marva $M$, Alicia W, Shlomo S, Marc B, Susan R, Bradley A, Susan $L$ and Stephen $R$ (2006): National Institute of Health, Neurocognitive outcomes in children with chronic kidney disease: Current findings and contemporary endeavors, 12 (3); P 208- 210.
5. Axton $S$ and Fugate $T$ (2009): Pediatric Nursing Care Plans, Care of children with urogenital dysfunction, $3^{\text {rd }}$ edition; P 357.

6. Bahbah M, El-Shafie A, Abou El Hana N, Deeb M, Khodeer S, Abdu-Allah $A$ and Hegran H (2011): Life Science Journal, Evaluation of bone turnover in children with chronic renal failure in Egypt, Menoufiya University, Egypt; 8 (4); P 156-158.

7. Ball $\mathbf{J}$ and Bindler $\mathbf{R}$ (2008): Pediatric Nursing Caring for Children, Alteration in genitourinary function, ch 25; P 3, 87:99, 110,116, 415, 1000, 1001.

8. Bradley A, Warady and Chadha V (2007): Pediatric Nephrology, Chronic kidney disease in children: the global perspective, 22 (1); P 19992006.

9. Brouhard BH, Donaldson LA, Lawry KW, McGowan KR, Drotar D, Davis I, Rose S, Cohn RA, and Tejani A (2000): Pediatric Transplantation, Cognitive functioning in children on dialysis and post-transplantation, 4 (1); P 261-267.

10. Duquette $P$, Hooper $S$, Wetherington $C$, Icard $P$, and Gipson D (2007): Journal of Pediatric Psychology, Intellectual and academic functioning in pediatric chronic Kidney Disease, 32 (8); P 1016.

11. El-Tayeb M, El Setouhy M, El Sayed H, Elshahawy Y, Sany D, Bichari W and Shaban A (2010): Screening of proteinuria in young adults: Is it worthwhile? Dialysis \& Transplantation, 39 (1); P 522-526.

12. Foster $B$ and Leonard $M$ (2004): American Journal of Clinical Nutrition, Measuring nutritional status in children with chronic kidney disease, 80 (4); P 801.

13. Gipson D, Hooper $S$, Duquette $P$, Wetherington C, Stellwagen K, Jenkins $T$ and Ferris M (2006): Child Neuropsychology, Memory and executive functions in pediatric chronic kidney disease, 12 (6); P 391.

14. Greenbaum L, Warady B and Furth S (2009): Reviews in Pediatrics Journal, Current Advances in Chronic Kidney Disease in Children: Growth, Cardiovascular, and Neurocognitive Risk Factors, 29 (4); P 425.

15. Gupta R, Mohammed A, Alenizi E and Ben Nekhi A (2011): Bone mineral density in Kuwaiti patients with end-stage renal disease, Conclusion, 20 (2); P 156-1

16. Hooper S, Gerson A, Butler R, Gipson D, Mendley S, Lande M, Shinnar S, Wentz A, Matheson M, Cox C, Furth S and Warady B (2011): The American Society of Nephrology, Neurocognitive functioning of children and 
adolescents with mild-to-moderate chronic kidney disease, 6 (1); P 1824.

17. Kligman R, Behrman R, Geme J, Stanton B and Schor $N$ (2011): Nelson Textbook of Pediatrics, Nephrology, chronic kidney disease, etiology, prognosis, $19^{\text {th }}$ edition, Saunders Elsevier, United States; p 1822,1823.

18. Mohamed E (2008): Self Care for School Age Children with Nephrotic Syndrome in Assuit University Hospital, thesis for $\mathrm{PhD}$, Assuit university, Egypt; p 96-104.

19. Ragab $M$ and Ragab A (2007): Journal of medical sciences, Assessment of lipid profile in Egyptian children with chronic kidney diseases on conservative therapy and those under regular dialysis, 7(5); P 825-829.

20. Rashid $R$, Neill $E$, Maxwell $H$, and Ahmed $S$ F (2007): British Journal of Nutrition, Growth and body composition in children with chronic kidney disease, 97 (1); P 232-238.

21. Warady B, Belden B and Kohaut E (1999): Pediatric Nephrology, Neurodevelopmental outcome of children initiating peritoneal dialysis in early infancy, results, 13 (1); P 759-765.

22. Whyte A and Fine $N$ (2008): Pediatrics in Review, Chronic Kidney disease in children, growth, American academy of pediatrics, 29 (10); P 336-338.

23. Youssef M (2012): Results of recombinant growth hormone treatment in children with end stage renal disease on regular hemodialysis, Saudi Journal of Kidney Disease and Transplantation, Zagazig University, Egypt, 23 (4); P 755-756. 